\title{
OPTIMASI KEBUTUHAN BATUBARA DALAM PEMBAKARAN BATU GAMPING DI DESA CEMPAKA MEKAR
}

\author{
${ }^{1}$ Sriyanti, ${ }^{2}$ Dudi Nasrudin Usman, ${ }^{3}$ Rudi Intan \\ 1,2,3 Universitas Islam Bandung, Bandung, Jawa Barat, Indonesia \\ E-mail: ${ }^{1}$ sriyanti.tambang@yahoo.com, ${ }^{2}$ dudi.n.usman@gmail.com, ${ }^{3}$ rudiintan99@gmail.com
}

\begin{abstract}
PT Damwoo Indo has limestone quality requirements ( $\mathrm{CaCO}_{3}$ grades) that will be burned with a minimum of $\mathrm{CaCO}_{3}$ grades by $50 \%$. As for the calcium oxide products produced also have standards from consumers, namely the minimum $\mathrm{CaO}$ grades that will be accepted by consumers, which is $80 \%$. The average coal calorific value is $6.294,70 \mathrm{kcal} / \mathrm{kg}$. Products produced from the combustion process have several types, namely: a). gaso, b). jogso, c). miso, and d). saso. Products with gaso and jogso quality will be marketed because they have been burned completely, but for the quality of the miso product will be burned again because the product has not been completely burned. Whereas products with saso quality will be waste and disposed of because the product is overburned. Maximum heating temperature to getsss quicklime products with $\mathrm{CaO}$ grades $>80 \%$ at the lowest $1.135^{\circ} \mathrm{C}$ and highest at $1.170^{\circ} \mathrm{C}$. The maximum heating temperature was achieved using coal with the lowest heating value of 4.804,13 kcal / $\mathrm{kg}$ and the highest was $6.197,52 \mathrm{kcal} / \mathrm{kg}$. From the results of the calculation of coal requirements needed in the limestone combustion process, the percentage of coal needs is an average of 12,26\%. This means that it takes 12,26\% of coal from calcium oxide products $(\mathrm{CaO})$ produced from the combustion process.

Keywords : Limestone, Purification, Kiln, Coal Needs, Heating Temperature, Calcium Oxide.
\end{abstract}

\begin{abstract}
Abstrak. PT Damwoo Indo memiliki syarat kualitas batugamping (kadar $\mathrm{CaCO}_{3}$ ) yang akan dibakar yaitu minimal kadar $\mathrm{CaCO}_{3}$ sebesar 50\%. Sedangkan untuk produk kapur tohor yang dihasilkan juga memiliki standar dari konsumen yaitu kadar $\mathrm{CaO}$ minimal yang akan diterima oleh konsumen yaitu sebesar $80 \%$. Nilai kalor batubara rata-rata adalah sebesar 6.294,70 kkal/kg. Produk yang dihasilkan dari proses pembakaran memiliki beberapa jenis yaitu : a). gaso, b). jogso, c). miso, dan d). saso. Produk dengan kualitas gaso dan jogso akan dipasarkan karena sudah terbakar secara sempurna, namun untuk kualitas produk miso akan dilakukan pembakaran kembali dikarenakan produk belum terbakar sempurna. Sedangkan untuk produk dengan kualitas saso akan menjadi limbah dan dibuang dikarenakan produk tersebut overburned. Suhu pemanasan maksimal untuk mendapatkan produk kapur tohor dengan kadar $\mathrm{CaO}>80 \%$ paling rendah $1.135^{\circ} \mathrm{C}$ dan paling tinggi $1.170^{\circ} \mathrm{C}$. Suhu pemanasan maksimal dicapai menggunakan batubara dengan nilai kalor paling rendah 4.804,13 kkal/kg dan paling tinggi $6.197,52 \mathrm{kkal} / \mathrm{kg}$. Dari hasil perhitungan kebutuhan batubara yang dibutuhkan dalam proses pembakaran batugamping, diperoleh persentase kebutuhan batubara rata-rata sebesar 12,26\%. Hal tersebut berarti dibutuhkan 12,26\% batubara dari produk kapur tohor (CaO) yang dihasilkan dari proses pembakaran.

Kata Kunci: Batu Gamping, Pemurnian, Kiln, Kebutuhan Batubara, Suhu Pemanasan, Kapur Tohor.
\end{abstract}




\section{Pendahuluan}

Industri pertambangan merupakan industri padat modal dan beresiko tinggi. Proses dalam kegiatan pertambangan meliputi semua tahapannya mulai dari awal yakni tahap prospeksi hingga tahapan pasca tambang, termasuk salah satu di dalamnya yaitu kegiatan pengolahan.

Berdasarkan peraturan perundangan Undang-Undang No 4 tahun 2009 tentang Pertambangan Mineral dan Batubara, setiap perusahaan yang bergerak di industri pertambangan wajib melakukan kegiatan pengolahan untuk bahan galian yang telah diambil atau telah dieksploitasi. PT Damwoo Indo adalah perusahaan yang bergerak di bidang pertambangan khususnya yakni kegiatan pengolahan dan pemurnian di Desa Cempakamekar, Kecamatan Padalarang, Kabupaten Bandung Barat, Provinsi Jawa Barat.

Kegiatan pengolahan adalah kegiatan yang bertujuan untuk memisahkan konsentrat dengan mineral pengotornya dan mereduksinya. Selain itu, kegiatan pengolahan dan pemurnian dilakukan untuk meningkatkan nilai jual dari material hasil penambangan dan memenuhi kebutuhan konsumen agar dapat bersaing dalam penjualan bahan atau material tambang tersebut.

Dalam proses pengolahan dan pemurnian batugamping di PT Damwoo Indo, batugamping yang telah melalui proses pengecilan dan penyeragaman ukuran, dicampur dengan batubara (bahan bakar) pada proses pembakaran di tungku tegak (kiln). Produk yang dihasilkan dari proses pembakaran adalah kapur tohor (kapur aktif) yang memiliki standar kadar $\mathrm{CaO}$. Standar kadar $\mathrm{CaO}$ dari kapur tohor yang ingin dicapai oleh perusahaan adalah $>80 \%$.

Berdasarkan latar belakang yang telah diuraikan, maka tujuan dalam penelitian ini yaitu untuk mengetahui suhu pemanasan yang optimal untuk mendapatkan produk kapur tohor dengan kadar $\mathrm{CaO}>80 \%$, untuk mengetahui nilai kalor batubara yang digunakan dalam proses pembakaran untuk mencapai suhu pemanasan yang optimal, danmengetahui banyaknya energi dan batubara yang digunakan dalam proses pembakaran.

Batugamping adalah batuan sedimen yang tersusun oleh senyawa kalsium karbonat $\left(\mathrm{CaCO}_{3}\right)$ dalam bentuk mineral kalsit. Batugamping di Indonesia sering disebut dengan istilah batu kapur atau dalam istilah luarnya biasa disebut dengan limestone yang paling sering terbentuk di perairan laut dangkal. Batubara adalah sedimen organik bahan bakar hidrokarbon padat yang terbentuk dari tumbuh-tumbuhan yang telah mengalami pembusukan secara biokimia, kimia dan fisika dalam kondisi bebas oksigen yang berlangsung pada tekanan serta temperatur tertentu pada kurun waktu yang sangat lama (waktu geologi).

Nilai kalor menunjukkan jumlah panas (heat) yang dihasilkan apabila sejumlah tertentu batubara dibakar. Nilai kalor ditentukan dari kenaikan suhu pada saat batubara dibakar dalam jumlah tertentu yang biasanya dinyatakan dalam kondisi $a d b$ dan dibakar didalam alat yang disebut calorimeter (bomb calorimeter) dengan udara berlebih. Hasil perhitungan ini dinyatakan dalam megajoule per kilogram $(\mathrm{MJ} / \mathrm{kg})$ atau kilo kalori per kilogram (kkal/kg).

Secara skematik shaft furnace atau tungku tegak (kiln) yang umum digunakan untuk proses kalsinasi yang 
dapat dilihat pada gambar dibawah ini. Bahan baku yang terdiri dari batu kapur dan batubara sebagai bahan bakarnya dimasukan dari bagian atas furnace. Sedangkan udara dihembuskan dari bagian bawah. Kapur bakar atau kapur tohor hasil kalsinasi di tarik keluar dari bagian bawah dari tungku pembakaran dan dikeluarkan secara bertahap (berkala). Tungku kalsinasi dapat dibagi dalam tiga zona, yaitu zona preheating, zona reaksi, dan zona cooling.

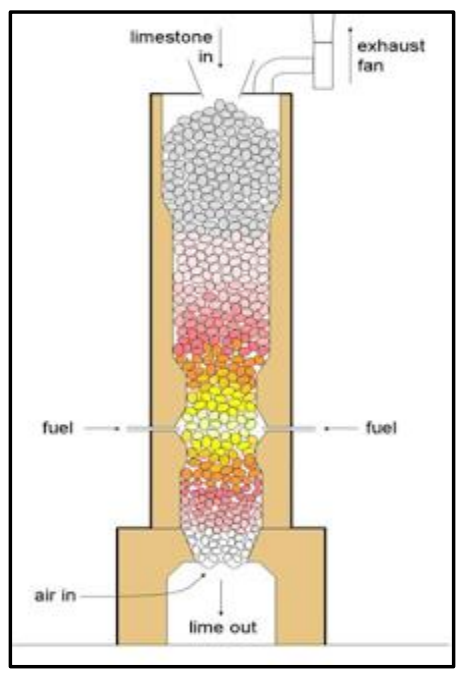

Gambar 1. Proses Kalsinasi Tungku Pembakaran

Sumber: Jurnal Tekmira, Vol 6. No 3, 2010.

Pada daerah Preheating Zone muatan padat batu kapur dan batubara akan mengalami pemanasan sampai temperatur sekitar 800 derajat celcius oleh gas panas yang bergerak berlawanan dari bawah ke bagian atas tungku. Pada daerah ini, belum terjadi reaksi kalsinasi maupun reaksi pembakaran dari batubara.

Pada daerah Reaction Zone terjadi reaksi pembakaran batubara dan dekomposisi dari batu kapur. Kapur bakar mengalami pemanasan berlebih dan diperkirakan mencapai temperatur 1000 derajat celcius. Gas yang meninggalkan daerah reaksi bertemperatur sekitar 900 derajat celcius. Temperatur gas yang keluar ini, 100 derajat celcius lebih tinggi dari pada temperatur material yang masuk pada daerah ini.

Cooling Zoned dan pada daerah ini kapur bakar didinginkan dengan udara yang bergerak berlawanan dari bagian bawah tungku. Pada daerah ini kapur bakar didinginkan sampai temperatur sekitar 100 derajat celcius.Agar terjadi pembakaran sempurna dari batubara, maka udara yang dihembuskan mencapai 25 persen lebih dari yang diperlukan.

Selama proses kalsinasi, Batu kapur, $\mathrm{CaCO}_{3}$ akan terurai menjadi kapur bakar dengan rumus kimia $\mathrm{CaO}$ (kalsium oksida) dan gas karbon dioksida, $\mathrm{CO}_{2}$ sesuai dengan reaksi berikut.

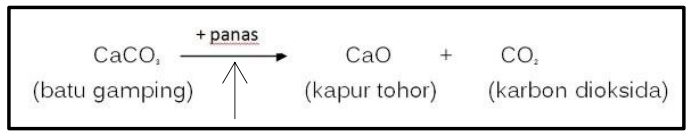

Gambar 2. Reaksi Kimia Kalsinasi

\section{Metodologi Penelitian}

Rancangan kegiatan penelitian terdiri dari lima tahapan yaitu tahap persiapan, tahap pengumpulan data, tahap pengolahan data, tahap analisis data dan tahap penyusunan laporan akhir. Pada tahap persiapan disusun rencana penelitian dan studi pustaka terkait proses perhitungan pencampuran batu bara, dan spesifikasi batu bara.

Pada tahap pengumpulan data, dikumpulkan data - data yang berhubungan dengan kegiatan penambangan oleh perusahaan dan proses Pembakaran batu bara. Teknik pengumpulan data yang dilakukan 
terdiri dari observasi lapangan, studi literatur, dan wawancara.

\section{Hasil Penelitian dan Pembahasan}

Setelah dilakukannya penelitian selama 25 hari, dapat diketahui bahwa jam kerja di PT Damwoo Indo mulai dari hari senin hingga hari jum'at adalah pukul 08.00 hingga pukul 16.00 WIB, dengan waktu istirahat selama 1 jam yaitu mulai pukul 12.00 hingga pukul 13.00 WIB kecuali hari jum'at yang memiliki waktu istirahat selama 2 jam dari pukul 11.00 hingga pukul 13.00 WIB. PT Damwoo Indo menerima batugamping setiap hari langsung dari tambang, namun hanya batu gamping dengan spesifikasi kadar $\mathrm{CaCO}_{3}>50 \%$. Hal tersebut disesuaikan dengan spesifikasi batubara (nilai kalor) yang dimiliki perusahaan untuk proses pembakaran.

Kualitas batubara yang digunakan dalam proses pembakaran batugamping bervariasi. Hal tersebut dikarenakan pengujian laboratorium untuk analisis proksimat dan pengujian nilai kalor batubara dilakukan setiap hari. Nilai kalor batubara paling rendah selama 25 hari penelitian adalah 5807,74 $\mathrm{kal} / \mathrm{gr}$, dan paling tinggi adalah 6723,61 $\mathrm{kal} / \mathrm{gr}$ dengan rata-rata nilai kalor $6294,70 \mathrm{kal} / \mathrm{gr}$. Berikut adalah data analisis laboratorium batubara yang dapat dilihat pada Tabel 1.
Tabel 1 Analisis Proksimat Batubara

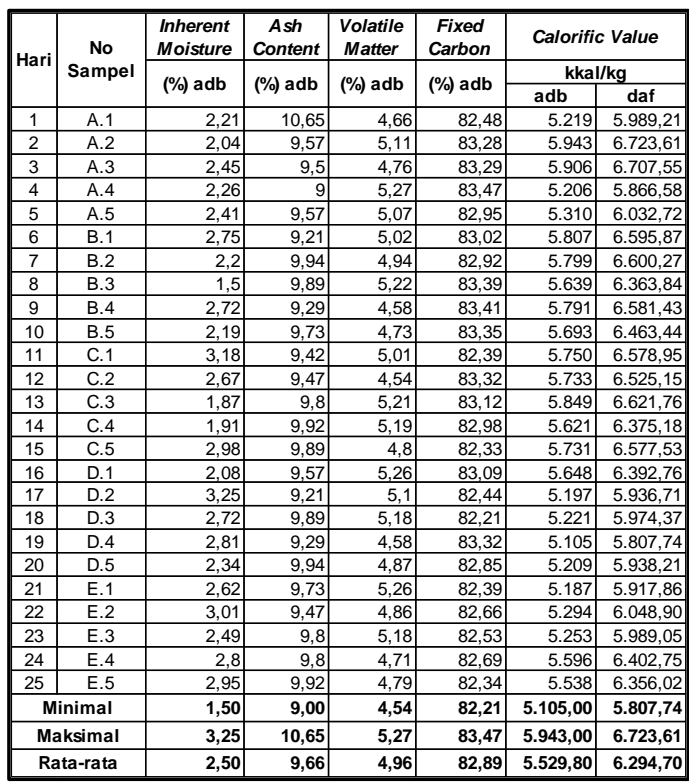

Berdasarkan hasil pengujian nilai kalor terhadap batubara, dilakukan perhitungan persentase kebutuhan batubara berdasarkan energi (kkal) yang dibutuhkan dalam proses pembakaran setiap $1 \mathrm{~kg}$ kapur tohor $(\mathrm{CaO})$. Menurut salah satu jurnal Teknologi Mineral dan Batubara Volume 6, "dibutuhkan energi panas sekitar 770 kkal untuk setiap $1 \mathrm{~kg}$ $\mathrm{CaO}$ yang diproduksi" (Boynton, 1999).

Energi panas yang dibutuhkan per satuan berat produk $\mathrm{CaO}$ yang diproduksi dapat dihitung dengan perhitungan berikut.

Energi panas $=770 \mathrm{kkal} \times \mathrm{W} \mathrm{CaO}$

Kebutuhan $\mathrm{BB}=$ Energi panas $/$ Nilai Kalor BB

Keterangan :

Energi panas $=$ energi panas untuk menghasilkan sejumlah produk $\mathrm{CaO}$ (kkal)

770 kkal $=$ energi yang dibutuhkan untuk menghasilkan $1 \mathrm{~kg}$ $\mathrm{CaO}$ (kkal)

$\mathrm{CaO}(\mathrm{kg})$

$\mathrm{W} \mathrm{CaO}=$ berat produk

Kebutuhan $\mathrm{BB}=\quad$ angka

kebutuhan batubara $(\mathrm{kg})$

Nilai kalor $\mathrm{BB}=$ nilai kalor batubara (kkal/kg atau kal/gr) 
Contoh perhitungan : (Sampel 1, Hari 1)

$$
\begin{aligned}
\text { Energi panas } & =770 \mathrm{kkal} \times 35.908,75 \mathrm{~kg} \\
& =27.649 .737,5 \mathrm{kkal} \\
\text { Kebutuhan } \mathrm{BB} & =\frac{27.649 .737,5 \mathrm{kkal}}{5.989,21 \mathrm{kkal} / \mathrm{kg}} \\
& =4.616,589626 \mathrm{~kg} \\
& =\frac{4.616,589626 \mathrm{~kg}}{35.908,75 \mathrm{~kg}} \times 100 \% \\
& =12,8564476 \% \\
\text { DB } & \text { hasil perhitungan }
\end{aligned}
$$

persentase kebutuhan batubara pada kiln 1 dan 2 berturut-turut dapat dilihat pada Tabel 2 dan Tabel 3 berikut.

Tabel 2 Kebutuhan Batubara Kiln 1

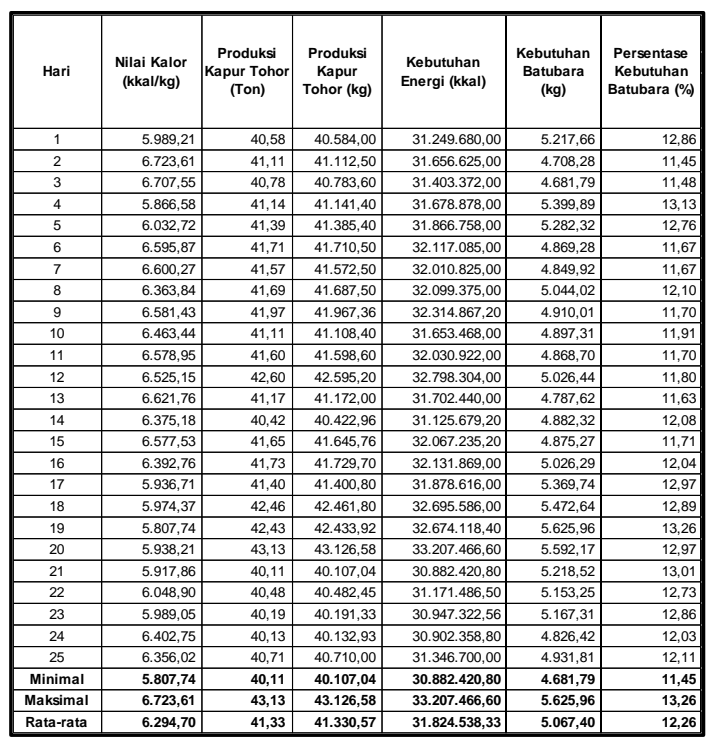

Tabel 3 Kebutuhan Batubara Kiln 2

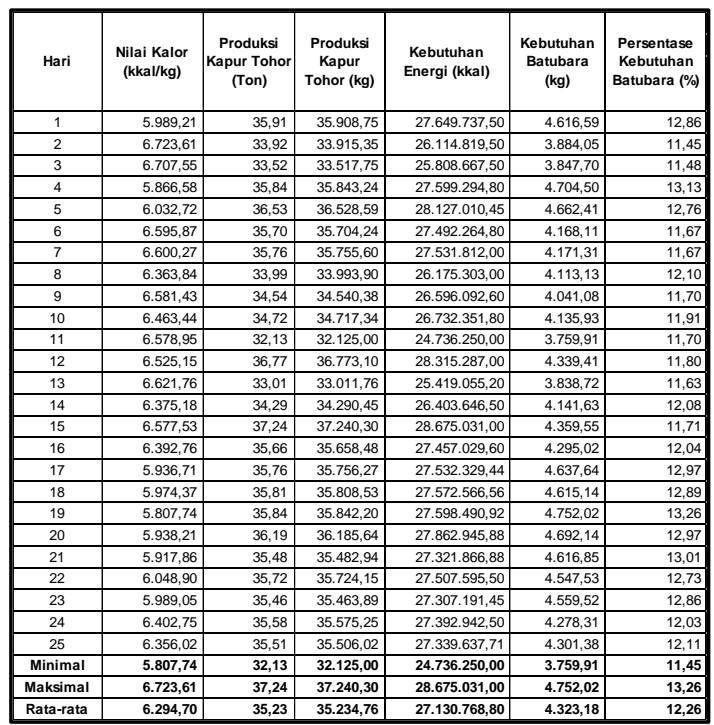

Tabel 4 Kebutuhan Batubara Kiln 1

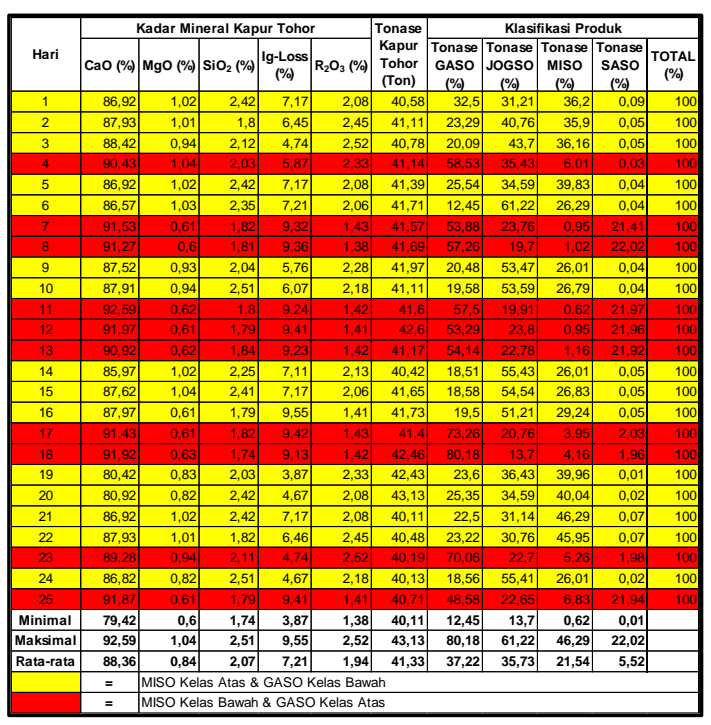

Tabel 5 Kebutuhan Batubara Kiln 2

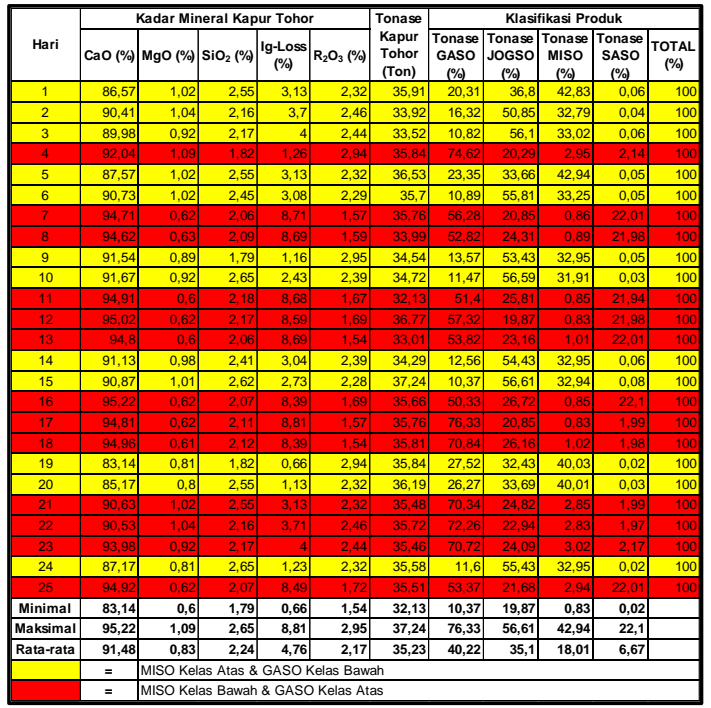

Data hasil analisis laboratorium $\mathrm{CaO}$ kapur tohor adalah persentase kadar minimal $\mathrm{CaO}$ kapur tohor yang keluar dari kiln 1 sebesar 79,42\% dan kadar maksimal $\mathrm{CaO}$ kapur tohor sebesar $92,59 \%$ serta rata-rata sebesar $88,36 \%$. Sedangkan persentase kadar minimal $\mathrm{CaO}$ kapur tohor yang keluar dari kiln 2 sebesar 83,14\% dan kadar maksimal $\mathrm{CaO}$ kapur tohor sebesar $95,22 \%$ serta rata-rata sebesar $91,48 \%$.

Selain itu, PT Damwoo Indo melakukan klasifikasi terhadap kapur tohor yang dihasilkan menjadi 4 (empat) kategori yakni kapur tohor dengan 
tingkat kematangan sempurna/tinggi (GASO), kapur tohor dengan tingkat kematangan sebagian (JOGSO), kapur tohor dengan tingkat kematangan tidak sempurna/rendah (MISO) dan kapur tohor dengan tingkat kematangan terlalu tinggi/overburned (SASO). Klasifikasi kapur tohor tersebut diatas ditentukan berdasarkan dari warna dan tingkat kekerasan kapur tohor. Warna kapur tohor dengan tingkat kematangan sempurna/tinggi adalah putih hingga kuning/coklat pucat. Sedangkan tingkat kekerasannya adalah mudah hancur. Kategori yang akan dikirim ke konsumen adalah kategori GASO dan JOGSO. Untuk kategori MISO akan dilakukan proses pembakaran kembali di kiln, namun untuk kapur tohor kategori SASO akan dibuang dan tidak akan dipasarkan atau menjadi waste.

Ada beberapa range terhadap variabel-variabel bebas diantaranya suhu pembakaran yang dibagi menjadi range rendah $\left(<1135^{\circ} \mathrm{C}\right)$ dan range tinggi $\left(>1135^{\circ} \mathrm{C}\right)$, serta batubara range rendah (5800-6300 kkal/kg) dan range tinggi (6300-6700 kkal/kg). Berdasarkan hasil percobaan, suhu pembakaran yang optimal adalah suhu pembakaran range tinggi $\left(>1135^{\circ} \mathrm{C}\right)$. Hal tersebut dikarenakan pengaturan suhu pembakaran range tinggi akan menghasilkan produk kapur tohor dengan kadar $\mathrm{CaO}>80 \%$ dan persentase berat produk kategori GASO $>50 \%$ serta memperkecil persentase berat produk kategori MISO. Produk kategori SASO yang akan dihasilkan juga tinggi, namun dapat dilihat dari data hasil percobaan bahwa banyaknya produk kategori SASO yang dihasilkan tidak terlalu banyak atau tidak melebihi banyaknya produk kategori GASO.

Nilai kalor batubara yang digunakan dalam proses pembakaran untuk mencapai suhu pembakaran yang optimal adalah nilai kalor batubara range rendah (5800-6300 $\mathrm{kkal} / \mathrm{kg})$. Penggunaan batubara dengan nilai kalor range tinggi dihindari karena akan menghasilkan banyak produk kategori SASO walaupun juga akan menghasilkan produk dengan kadar $\mathrm{CaO}$ yang tinggi $(>80 \%)$.

Banyaknya batubara yang dibutuhkan dalam proses pembakaran akan lebih banyak apabila menggunakan batubara dengan nilai kalor range rendah (5800-6300 kkal/kg) dibandingkan menggunakan batubara dengan nilai kalor range tinggi (6300-6700 kkal/kg). Hal tersebut dikarenakan banyaknya batubara yang dibutuhkan tergantung nilai kalor dari batubara. Namun dengan pengaturan tersebut diatas, produk yang dihasilkan akan lebih banyak produk kategori GASO dengan kadar $\mathrm{CaO}$ $>80 \%$.

Persentase produk kategori GASO akan lebih banyak dibandingkan dengan kategori MISO dikarenakan kadar $\mathrm{CaO}$ yang lebih tinggi dibandingkan dengan data pengamatan lainnya. Dapat dilihat pada kiln 1 yakni Tabel 4, data pengamatan yang berwarna merah menunjukkan kadar $\mathrm{CaO}$ yang $>90 \%$ dan dapat dilihat juga bahwa data tersebut menunjukkan persentase produk kategori GASO yang tinggi dan kategori MISO yang rendah. Pada kiln 2 dapat dilihat juga bahwa tingginya kadar $\mathrm{CaO}$ menentukan tingginya persentase produk kategori GASO dan rendahnya produk kategori MISO yang ditandai dengan kolom tabel berwarna merah. Namun ada beberapa data yang menunjukkan kadar $\mathrm{CaO}$ yang tinggi namun tidak menghasilkan persentase produk kategori GASO yang tinggi dan kategori MISO yang rendah. Data tersebut dianggap sebagai data yang tidak valid 
dan membutuhkan variabel lainnya untuk membuktikan data-data tersebut.

\section{Kesimpulan}

\section{Kesimpulan}

Berdasarkan tujuan dari penelitian yang telah dilakukan, dapat disimpulkan yaitu hasil percobaan dan perhitungan, suhu pemanasan yang maksimal untuk mendapatkan produk kapur tohor dengan kadar $\mathrm{CaO}>80 \%$ dan persentase produk GASO (persentase berat $>50 \%$ ) paling rendah adalah $1135^{\circ} \mathrm{C}$ dan paling tinggi adalah $1170^{\circ} \mathrm{C}$.

Nilai kalor batubara yang digunakan dalam proses pembakaran untuk mencapai suhu pemanasan yang maksimal paling kecil 4.804,13 kkal/kg dan paling tinggi $6.197,52 \mathrm{kkal} / \mathrm{kg}$.

Berdasarkan perhitungan kebutuhan energi, rata-rata energi yang dibutuhkan dalam proses pembakaran pada kiln 1 adalah sebesar 31.824.538,33 kkal dan pada kiln 2 sebesar $27.130 .768,80 \mathrm{kkal}$. Sedangkan rata-rata batubara yang dibutuhkan dalam proses pembakaran pada kiln 1 adalah sebesar $5.067,40 \mathrm{~kg}$ dan pada kiln 2 sebesar $4.323,18 \mathrm{~kg}$.

\section{Saran}

Berdasarkan dari hasil penelitian yang telah dilakukan di PT Damwoo Indo, peneliti menyarankan beberapa hal terkait pada proses pembakaran yang dilakukan, antara lain untuk mendapatkan produk kapur tohor dengan kadar $\mathrm{CaO}$ dan persentase produk kategori GASO yang tinggi, tidak diperlukan waktu pembakaran selama 24 jam. Berdasarkan percobaan dan perhitungan yang telah dilakukan, proses pembakaran dapat dilakukan selama 1821 jam dengan suhu pemanasan yang maksimal serta penggunaan nilai kalor yang disesuaikan. Hal tersebut dapat menghemat waktu pembakaran dan konsumsi batubara.

Untuk mencapai produk GASO yang maksimal, dapat dilakukan blending batubara untuk mendapatkan batubara dengan nilai kalor yang optimal dan untuk mencapai suhu pemanasan yang maksimal. Blending batubara dilakukan dengan mencampurkan batubara dengan nilai kalor yang tinggi dengan yang rendah.

Untuk produk kapur tohor yang telah mencapai kadar $\mathrm{CaO}>80 \%$ namun belum maksimal dalam menghasilkan produk dengan persentase produk kategori GASO, dapat dilakukan pembakaran dengan waktu pembakaran yang lebih lama (>24 jam) dengan suhu pemanasan maksimal dan nilai kalor batubara yang sama. Untuk penelitian lebih lanjut, disarankan untuk melengkapi data penelitian dengan data uji laboratorium batugamping (termasuk kadar air) serta data pengamatan produk setiap 3 atau 6 jam sekali agar dapat mengetahui waktu pembakaran efektif dengan suhu pemanasan dan nilai kalor yang tetap.

Pemilihan dan seleksi batugamping (bahan baku) di lokasi penambangan sebaiknya dilakukan secara teliti dan ketat oleh checker. Hal tersebut dilakukan untuk menghindari masuknya batugamping (bahan baku) dengan kualitas yang tidak sesuai dengan permintaan dari PT Damwoo Indo karena dapat berdampak pada penggunaan antrasit, pengaturan suhu pembakaran, dan produk yang akan dihasilkan dari proses pembakaran tersebut.

Pemilihan atau seleksi produk kapur tohor hasil proses pembakaran sebaiknya dilakukan lebih teliti dan 
dilakukan oleh operator yang berpengalaman. Hal tersebut berpengaruh terhadap produk kapur tohor yang dipilih oleh selektor. Pemilihan yang dilakukan sebaiknya tepat karena apabila produk yang sudah terbakar sempurna (GASO) dipilih untuk dilakukan pembakaran kembali, maka akan terjadi proses pembakaran kembali produk kapur tohor yang sudah terbakar sempurna dan akan mengakibatkan produk kapur tohor menjadi overburned (SASO). Produk tersebut tidak akan diterima oleh konsumen karena tidak sesuai dengan kebutuhan. Begitu pula sebaliknya apabila produk kapur tohor yang belum terbakar sempurna dipilih dan dimasukkan ke kategori produk kapur tohor yang terbakar sempurna dan dikirim ke konsumen. Hal tersebut akan mengakibatkan pengembalian (reject) oleh konsumen karena produk kapur tohor tidak sesuai dengan permintaan.

Masih ada variabel penelitian yang kurang untuk menentukan volume produk kategori GASO serta menentukan suhu pemanasan optimal. Akibatnya, dapat diasumsikan bahwa suhu pemanasan tidak sepenuhnya berpengaruh dalam proses pembakaran batugamping. Disarankan untuk penelitian selanjutnya untuk melengkapi data dari variabel yang kurang tersebut seperti data uji laboratorium dan kadar dari batugamping (bahan baku) meliputi kadar air, $\mathrm{CaCO}_{3}$, kekerasan, dan lainlain.

\section{Daftar Pustaka}

Aziz, Muchtar. 2010. Batu Kapur dan Peningkatan Nilai Tambah Serta Spesifikasi Untuk Industri. Jurnal Teknologi Mineral dan Batubara Volume 06 Nomor 3 Bulan Juli 2010

Hal 116-131 : Bandung.
Badan Pusat Statistik (BPS). 2017. Kabupaten Bandung Barat Dalam Angka. 978-602-710-841-7.

Kabupaten Bandung Barat : Badan Pusat Statistik Kabupaten Bandung Barat. 